\title{
Reliability and Validity of a Chinese Version of the Students' Attitudes toward Physical Education Scale and Its Related Factors
}

\author{
Huanhuan Hu1, Jiali Duan², Guan Wang2, Takashi Arao ${ }^{3}$ \\ ${ }^{1}$ Lab of Exercise Epidemiology, Graduate School of Sport Sciences, Waseda University, Tokyo, Japan \\ ${ }^{2}$ Institute of School Health, Beijing Center for Diseases Control and Prevention, Beijing, China \\ ${ }^{3}$ Lab of Exercise Epidemiology, Faculty of Sport Sciences, Waseda University, Tokyo, Japan \\ Email: tarao@waseda.jp
}

Received 21 August 2014; revised 20 September 2014; accepted 8 October 2014

Copyright (C) 2014 by authors and Scientific Research Publishing Inc.

This work is licensed under the Creative Commons Attribution International License (CC BY). http://creativecommons.org/licenses/by/4.0/

(c) (i) Open Access

\section{Abstract}

This study aimed to examine the reliability and validity of a Chinese version of the Students' Attitudes toward Physical Education Scale (SPEA), and to ascertain the associations between student attitudes toward physical education and gender, grade levels, school, and area. In 2013, a crosssectional study was conducted in eight middle schools in Beijing, China. A sample of 1793 students was enrolled. Cronbach's alpha and intraclass correlation coefficients (ICC) were performed to evaluate the scale's internal and test-retest reliability. Construct validity was assessed with confirmatory factor analysis. Linear mixed models were used to examine the associations of attitude scores with gender, grade, school, and area (urban and suburban). Our results showed high reliability (Cronbach's alpha $=0.90$, ICC $=0.94 ; 95 \% \mathrm{CI}, 0.92-0.96$ ) of the SPEA. For the construct validity, results of confirmatory factor analysis showed an acceptable model fit. Overall, the mean of the attitude scores was $75.5 \pm \mathbf{1 3 . 4}$ out of 100 . The attitude scores were found to be statistically different between grade levels, schools, and areas. No differences were found for gender. This study provides evidence that the SPEA is acceptable for the assessment of the attitude toward physical education in Chinese students. The school plays a more important role in the student attitudes than school locations (urban or suburban) in our study. For better understanding of students' attitudes toward physical education, further studies that focus on the environment of physical education in schools, and use more representative samples of schools from various locations are warranted.

\section{Keywords}

Physical Education, Physical Activity, Attitude, Middle School

How to cite this paper: Hu, H. H., Duan, J. L., Wang, G., \& Arao, T. (2014). Reliability and Validity of a Chinese Version of the Students' Attitudes toward Physical Education Scale and Its Related Factors. Advances in Physical Education, 4, $181-189$. 


\section{Introduction}

There is increasing evidence that childhood physical activity is positively associated with a range of beneficial childhood health and fitness outcomes (Hills et al., 2011; Pate \& O’Neill, 2008). School physical education is seen as a societal institution with a responsibility to promote physical activity in youth that reaches most schoolaged youths. Physical education classes can provide youths with substantial amounts of physical activity, which may be particularly important for those who have little or no physical activity in daily life (Gallahue \& Donnelly, 2003).

Understanding student attitudes toward physical education can aid teachers in improving teaching content and forming positive attitudes toward physical education among students (Cothran \& Ennis, 1998). Emerging evidence has shown that students who show a more positive attitude toward physical activity in physical education are more likely to participate in physical activity outside of school (Portman, 1995; McKenzie, 2003).

Different scales for assessing student attitudes have been reported in studies of physical education. In a review of attitude research in physical education, Silverman and Subramaniam (1999) found that these instruments either failed to follow proper instrument validation steps or used attitude theory as a guiding framework in assessing the attribute, which may have contributed to the mixed findings of attitude studies in the physical education area (Biddle \& Mutrie, 2001). After realizing the inadequacy of these instruments, a two-component instrument grounded in attitude theory was developed and validated (Subramaniam \& Silverman, 2000; Subramaniam \& Silverman, 2007). The Students’ Attitudes toward Physical Education Scale (SPEA) measures students’ enjoyment (affect) and perceived usefulness (cognition) of physical education in their present school with their current physical education teachers (Subramaniam \& Silverman, 2000).

Until now, the SPEA has not been available in Chinese. Development of a Chinese version of the SPEA would allow Chinese investigators to participate in international research studies when this scale is proposed. With this instrument developed to successfully measure the construct in a physical education setting, researchers can draw sound conclusions about student attitudes (Subramaniam \& Silverman, 2000).

The main objective of this study was to examine the reliability and validity of a Chinese translation of the scale in students. The secondary objectives were to use the Chinese SPEA to measure middle school students' attitudes toward physical education and to ascertain the relationships between student attitudes toward physical education and gender, grade level, school, and area (urban or suburban).

\section{Methods}

\subsection{Design and Setting}

This observational cross-sectional study was conducted in 8 middle schools in Beijing, China.

\subsection{SPEA}

The 20-item SPEA was designed to measure student attitudes toward physical education on affect and cognition (Subramaniam \& Silverman, 2000). The two components were labeled Enjoyment and Usefulness, respectively. Each component had two sub-domains: the physical education teacher and the curriculum. Response choices were on a 5-point Likert response scale ranging from "strongly disagree” (1) to "strongly agree” (5), with a total possible score of 100 points for overall attitude. A higher score indicates a more positive attitude. The validation of the instrument included an elicitation study, a pilot study, a content validity study, and a reliability and validity study in middle school students. Validation of scores from the instrument demonstrated psychometric evidence of validity and reliability (Subramaniam \& Silverman, 2000).

\section{Translation and Adaptation of the SPEA}

We received permission from the original author to use of the SPEA. A forward and back translation was carried out to confirm accuracy. The instrument was independently translated into Chinese by a graduate student majoring in English and a medical doctor, both of whom were fluent in English and Chinese. Two forward translations were synthesized into one Chinese version by the first author of this manuscript. Culture adaptation was achieved during a consensus meeting attended by experts in school health. The reverse translation from Chinese to English was carried out by another medical doctor who was not involved in developing the initial version. The original and the back-translated English versions were compared and inconsistencies were resolved through consensus meetings. The Chinese version was finalized when there were no disputes or new sugges- 
tions.

\subsection{Participants}

Participants for this study were students in grades 7, 8, and 9 from eight middle schools in two school districts in Beijing, China.

First, 2 school districts were contacted to participate in this study (1 from urban districts and 1 from suburban districts); Then, four middle schools were contacted and requested to participate in this study from each selected district. In each school, 2 classes were randomly selected from each grade. The students who underwent physical education were invited to participate in this study.

A total of 1793 students from 8 schools consented to participate. Of these, 1717 completed the questionnaires. The mean age was $13.3 \pm 1.0$ years: $51.8 \%$ (883 of 1704 ) were boys, and $47.9 \%$ ( 823 of 1717 ) were from suburban schools.

\section{Procedures}

The principals of selected schools were informed about the objectives and procedures of the study. Then the principals introduced the study team to the school nurses, physical education teachers, and students. The instrument was administered during class recess in the classroom. The school nurses who have received training for this study were available to assist if students had questions on completing the instrument. It took participants an average person 15 minutes to finish the scale. For test-retest reliability, the participants in one of the schools completed the SPEA a second time 2 weeks later, giving a final sample of 146 students for test-retest data for the Chinese SPEA (67 girls, 79 boys; mean age $13.6 \pm 1.1$ years). We were not able to include the other schools for a second measurement because of a lack of available time slots.

\subsection{Ethical Considerations}

The ethical review boards in the Beijing Center for Disease Control and Prevention and Waseda University granted permission for us to conduct this study. Informed consent was obtained from the principals, teachers, students, and their custodians prior to data collection. An information sheet describing the study was available for all students. Before instrument administration, the students were informed that the survey was voluntary and that they could choose to participate or not. The questionnaire was completed anonymously by students.

\subsection{Data Management and Statistical Analysis}

Data were double-entered and cross-checked using Epi Info version 6 statistical software. Descriptive statistics such as means and standard deviations were used where appropriate.

The scale's internal consistency reliability was determined by calculating Cronbach's alpha. Internal reliability is acceptable if Cronbach's alpha coefficient is greater than 0.70 (Bland \& Altman, 1997). Test-retest reliability was evaluated using the intraclass correlation coefficient (ICC) and an ICC value of 0.40 represents moderate, 0.60 good, and 0.80 high agreement (Wilson et al., 2000).

Construct validity was assessed with confirmatory factor analysis (CFA) using the maximum likelihood estimation method. Based on previous findings and a preliminary construct validity analysis of the Chinese SPEA, both the two-factor clusters (Enjoyment and Usefulness) and sub-factor clusters models (enjoyment teacher (ET), enjoyment curriculum (EC), usefulness teacher (UT), and usefulness curriculum (UC)) of the SPEA were estimated.

A number of indices of model fit were proposed (Browne \& Cudeck, 1993; MacCallum \& Hong, 1997). In this study, the root mean square error of approximation (RMSEA), Comparative Fit Index (CFI), Normed Fit Index (NFI), Goodness of Fit Index (GFI), and Adjusted Goodness of Fit Index (AGFI) were used as indexes of model fit. For the RMSEA, values of less than 0.05 are considered to be indicative of close fit, values of 0.08 demonstrate a fair fit, and values greater than 0.10 indicate poor fit (Browne \& Cudeck, 1993). For the CFI and NFI, values greater than 0.90 are considered to be indicative of an acceptable model fit (Suhr, 2006). Values for GFI and AGFI are from zero to one with values closer to one indicating a better model fit (Byrne, 1989).

We used linear mixed models to examine the associations of attitude scores with gender, grade, school, and area (urban or suburban). These models accounted for potential correlations among students within the same school. Statistical analyses were conducted using SAS version 9.3 (SAS Institute, Inc., Cary, North Carolina). 


\section{Results}

\subsection{Internal Consistency and Test-Retest Reliability}

Cronbach's alpha for the Chinese SPEA was 0.90 for the complete instrument, representing an acceptable internal consistency. Retests for reliability were completed by 146 students who completed the first questionnaires. The ICC was 0.94 (95\% CI, 0.92 - 0.96) for the Chinese SPEA total score. The ICC of individual items ranged from 0.63 to 0.91 . All of these ICCs were in the good to excellent reliability range.

\subsection{Construct Structure}

We first tested the two primary factors (Enjoyment and Usefulness) with CFA. In the first analysis, RMSEA = 0.206 , CFI $=0.720$, NFI $=0.718$, GFI $=0.82$, and AGFI $=0.416$. The analyses yielded low values of fit. Thus, we further analyzed the two sub factors (physical education teacher and curriculum) of each primary factor (Enjoyment and Usefulness). In the second CFA, results showed that RMSEA $=0.099$, CFI $=0.929$, NFI $=0.925$, $\mathrm{GFI}=0.83$, and AGFI $=0.79$. The new fit indices displayed a relatively better fit when compared to the previous analysis. The maximum likelihood factor loadings for all items were greater than 0.30 , furthering support this model (Table 1).

\section{Table 1. Instrument items and confirmatory structure coefficients.}

\begin{tabular}{|c|c|c|c|c|}
\hline \multirow{2}{*}{ Item } & \multicolumn{2}{|c|}{ Enjoyment } & \multicolumn{2}{|c|}{ Usefulness } \\
\hline & Curriculum & Teacher & Curriculum & Teacher \\
\hline $\begin{array}{l}1 \text { The games I learn in physical education make my } \\
\text { physical education class interesting for me. }\end{array}$ & 0.96 & & & \\
\hline $\begin{array}{l}2 \text { The games I learn in my physical education class make } \\
\text { learning unpleasant for me. }\end{array}$ & 0.90 & & & \\
\hline $\begin{array}{l}3 \text { The games I learn in my physical education class get } \\
\text { me excited about physical education. }\end{array}$ & 0.72 & & & \\
\hline $\begin{array}{l}5 \text { I feel the games I learn in physical education make } \\
\text { my physical education class boring for me. }\end{array}$ & 0.70 & & & \\
\hline $\begin{array}{l}20 \text { I feel the games I learn in my physical education } \\
\text { class make learning fun for me. }\end{array}$ & 0.92 & & & \\
\hline $\begin{array}{l}9 \text { My physical education teacher makes my physical } \\
\text { education class interesting for me. }\end{array}$ & & 0.94 & & \\
\hline $\begin{array}{l}11 \text { I feel my physical education teacher makes learning } \\
\text { in my physical education class fun for me. }\end{array}$ & & 0.95 & & \\
\hline $\begin{array}{l}12 \text { I feel my physical education teacher makes my } \\
\text { physical education class boring for me. }\end{array}$ & & 0.94 & & \\
\hline $\begin{array}{l}15 \text { My physical education teacher makes learning in } \\
\text { my physical education class unpleasant for me. }\end{array}$ & & 0.96 & & \\
\hline 19 My physical education teacher gets me excited about physical education. & & 0.95 & & \\
\hline 6 I feel the games I learn in my physical education class are useless to me. & & & 0.76 & \\
\hline 7 The games I learn in my physical education class seem important to me. & & & 0.80 & \\
\hline 10 The games I learn in my physical education class are useful to me. & & & 0.86 & \\
\hline 13 I feel the games I learn in my physical education class are valuable to me. & & & 0.72 & \\
\hline 14 The games I learn in my physical education class seem unimportant to me. & & & 0.70 & \\
\hline $\begin{array}{l}4 \text { My physical education teacher makes my physical } \\
\text { education class seem unimportant to me. }\end{array}$ & & & & 0.56 \\
\hline $\begin{array}{l}8 \text { My physical education teacher makes my physical } \\
\text { education class seem important to me. }\end{array}$ & & & & 0.61 \\
\hline $\begin{array}{l}16 \text { My physical education teacher makes my } \\
\text { physical education class useful for me. }\end{array}$ & & & & 0.86 \\
\hline $\begin{array}{l}17 \text { I feel my physical education teacher makes learning in } \\
\text { my physical education class valuable for me. }\end{array}$ & & & & 0.85 \\
\hline $\begin{array}{l}18 \text { I feel my physical education teacher makes learning in } \\
\text { my physical education class useless for me. }\end{array}$ & & & & 0.82 \\
\hline
\end{tabular}




\subsection{Students' Attitudes toward Physical Education}

The descriptive data for students' attitudes toward physical education in gender, grade, school, area (urban or suburban), and all are shown in Table 2 to Table 4. Overall, the mean of the attitude scores was $75.5 \pm 13.4$ out of 100 . The overall values ranged from $70.5 \pm 14.7$ to $85.4 \pm 11.4$ at school levels (Table 2 ). As shown in Table 3 , descriptive data showed that students in suburban schools had a higher mean score, and students in grade 9 had a lower mean score than those students in the other two grades. The overall values were $18.9 \pm 4.5$ for ET, $19.8 \pm 4.2$ for EC, $17.8 \pm 2.6$ for UT, and 19.0 \pm 4.2 for UC out of a total possible score of 25. Means and standard deviations for the subscales are reported in Table 4.

The covariance parameter estimates of linear mixed models indicated that $9.5 \%$ of the variability in student physical education attitude was accounted for by the schools $(Z=1.77, P=0.038)$ and were not significant for grade or area. The overall attitude scores were found to be statistically different between grades, schools, and areas. Compared to model 2, model 3 showed that the school played a more important role in student attitude than school location (urban, suburban) in our study (Table 5). The interaction effects of grade $\times$ school were also statistically significant $(P<0.05)$. There were no significant differences for gender. A further subscale analysis was carried out. For UT and ET, attitude scores were found to be statistically different between schools and areas $(P<0.05)$. For UC and EC, attitude scores were found to be statistically different between grades, schools, and areas $(P<0.05)$.

\section{Discussion}

This study validates the Chinese version of SPEA for use in Chinese students. The associations of students' attitudes toward physical education with gender, grade levels, schools, and areas were also examined.

Our results showed high reliability (Cronbach's alpha =0.90, ICC = 0.94; 95\% CI, $0.92-0.96$ ) of the SPEA. For construct validity, factor analysis results indicated that the two primary factor structure (Enjoyment, and

Table 2. Overall means and standard deviations for school.

\begin{tabular}{ccccc}
\hline Area & School & Female & Male & Both \\
\hline & 1 & $75.5(12.7)$ & $73.9(14.9)$ & $74.7(13.8)$ \\
Urban & 2 & $68.6(14.7)$ & $73.3(13.9)$ & $70.5(14.7)$ \\
& 3 & $76.2(12.4)$ & $75.1(12.5)$ & $75.4(12.8)$ \\
& 4 & $73.7(11.5)$ & $75.6(12.5)$ & $74.7(12.0)$ \\
\hline Suburban & 5 & $73.2(12.6)$ & $75.3(13.6)$ & $73.8(13.2)$ \\
& 6 & $72.7(12.7)$ & $74.7(13.6)$ & $78.2(11.5)$ \\
\hline
\end{tabular}

Note: Values are means, and standard deviations.

Table 3. Overall means and standard deviations for gender, grade, and region level.

\begin{tabular}{ccccc}
\hline & Female & Male & Suburban & Urban \\
\hline Grade 7 & $75.3(11.9)$ & $77.3(13.1)$ & $78.4(12.4)$ & $74.1(12.4)$ \\
Grade 8 & $76.6(12.8)$ & $76.1(13.9)$ & $79.1(13.3)$ & $73.8(13.1)$ \\
Grade 9 & $73.0(14.4)$ & $75.5(13.3)$ & $74.8(13.0)$ & $73.5(15.0)$ \\
All & $75.0(13.1)$ & $76.3(13.5)$ & $77.5(13.0)$ & $73.8(13.5)$ \\
\hline
\end{tabular}

Note: Values are means, and standard deviations. 
Table 4. Means and standard deviations for gender, region and grade level for enjoyment (teacher and curriculum) and perceived usefulness (teacher and curriculum).

\begin{tabular}{|c|c|c|c|c|c|}
\hline & & Grade 7 & Grade 8 & Grade 9 & All \\
\hline \multirow{5}{*}{$\begin{array}{l}\text { Enjoyment } \\
\text { (teacher) }\end{array}$} & Female & $18.7(4.3)$ & $19.2(4.3)$ & $18.4(4.6)$ & $18.7(4.4)$ \\
\hline & Male & $19.2(4.8)$ & $19.1(4.5)$ & $19.2(4.6)$ & $19.2(4.6)$ \\
\hline & Suburban & $19.4(4.8)$ & $20.0(4.2)$ & $19.0(4.3)$ & $19.5(4.5)$ \\
\hline & Urban & $18.4(4.3)$ & $18.4(4.5)$ & 18.5 (4.9) & $18.5(4.6)$ \\
\hline & All & $18.9(4.5)$ & $19.1(4.4)$ & $18.7(4.7)$ & $18.9(4.5)$ \\
\hline \multirow{5}{*}{$\begin{array}{l}\text { Enjoyment } \\
\text { (curriculum) }\end{array}$} & Female & 20.2 (3.7) & $20.0(4.1)$ & $18.7(4.6)$ & $19.7(4.2)$ \\
\hline & Male & $20.4(4.2)$ & $20.2(4.3)$ & $19.6(4.0)$ & $20.1(4.2)$ \\
\hline & Rural & $20.7(4.0)$ & $20.6(4.2)$ & $19.4(4.0)$ & $20.2(4.1)$ \\
\hline & Urban & 19.9 (3.9) & $19.6(4.2)$ & $18.9(4.7)$ & 19.5 (2.6) \\
\hline & All & $20.3(4.0)$ & $20.1(4.2)$ & $19.1(4.4)$ & $19.8(4.2)$ \\
\hline \multirow{5}{*}{$\begin{array}{l}\text { Usefulness } \\
\text { (teacher) }\end{array}$} & Female & $17.5(2.5)$ & $18.2(2.5)$ & 17.5 (2.6) & $17.7(2.6)$ \\
\hline & Male & $17.9(2.8)$ & $17.7(4.3)$ & $17.9(2.6)$ & $17.8(2.7)$ \\
\hline & Suburban & $18.0(2.9)$ & $18.1(2.6)$ & $17.8(2.5)$ & $18.0(2.7)$ \\
\hline & Urban & $17.5(2.4)$ & $17.7(2.6)$ & $17.6(2.8)$ & $17.6(2.6)$ \\
\hline & All & $17.7(2.7)$ & $17.9(2.6)$ & $17.7(2.6)$ & $17.8(2.6)$ \\
\hline \multirow{5}{*}{$\begin{array}{l}\text { Usefulness } \\
\text { (curriculum) }\end{array}$} & Female & 19.0 (3.9) & $19.1(4.0)$ & $18.4(4.2)$ & $18.9(4.0)$ \\
\hline & Male & $19.4(4.1)$ & $19.3(4.4)$ & $18.7(4.3)$ & $19.1(4.2)$ \\
\hline & Suburban & 20.2 (3.9) & $20.2(4.1)$ & $18.6(4.3)$ & $19.7(4.1)$ \\
\hline & Urban & $18.2(4.0)$ & $18.3(4.2)$ & $18.4(4.4)$ & $18.3(4.2)$ \\
\hline & All & $19.1(4.0)$ & $19.2(4.2)$ & 18.5 (4.3) & $19.0(4.2)$ \\
\hline
\end{tabular}

Note: Values are means, standard deviations.

Table 5. Estimates from mixed linear models predicting students’ attitudes.

\begin{tabular}{ccccc}
\hline & & Model 1 & Model 2 & Model 3 \\
\hline Fixed effects & & & \\
& Intercept & $74.06(1.61)^{*}$ & $75.7(0.77)^{*}$ & $78.44(2.10)^{*}$ \\
& Sex & $1.17(0.64)$ & $1.08(0.65)$ & $1.13(0.62)$ \\
Grade & $1.86(0.79)^{*}$ & $1.86(0.81)^{*}$ & $5.71(2.76)^{*}$ \\
School & & & $13.24(2.56)^{*}$ \\
Random effects & School × grade & & & $17.44(3.45)^{*}$ \\
Model fit & Area & & $3.54(0.66)^{*}$ & 12575.9 \\
AIC & & $17.15(9.69)^{*}$ & & 12581.2 \\
\hline
\end{tabular}

Note: "Statistically significant, $P<0.05$; Values based on SAS Proc Mixed. Entries show parameter estimates with standard errors in parentheses. 
Usefulness) was a low fit to the observed data. However, a further subscale (UT, ET, UC, and UT) analysis showed a relatively better model fit. It was acknowledged that, in confirmatory factor analysis, any model can be rejected if the sample size is large enough, because hypothesized models are best regarded as approximations to reality rather than exact statements of truth (Marsh et al., 1988). Previous studies have shown that the NFI, GFI, and AGFI values had high sensitivity toward sample size and argued that RMSEA value was relatively independent of sample size (Marsh et al., 1988; Fan \& Sivo, 2007; Widaman \& Thompson, 2003). From this perspective, in this study, the subfactor structure is acceptable. This was further supported by the factor loadings which were greater than 0.30 for all items.

In their previous study, Subramaniam and Silverman (2000) demonstrated that the instrument produced valid scores for both primary factors and two of the subfactors (teacher and curriculum). Although the potential reasons for the difference in the results are unclear, one possible explanation might be caused by culture-based differences in students' perceptions of teachers (Adams \& Sargent, 2009; Roberts \& Tuleja, 2008). As education in China is much more "teacher centered and content oriented" than in Western countries, which feature "student centered and learning oriented" education, the educational experiences of students in China may lead Chinese students to be sensitive to the differences in teacher and curriculum. Further study is needed to validate the structure of the SPEA.

Students' attitudes toward physical education have been studied. Several findings in this study are consistent with previous studies. Similar to findings from Subramaniam and Silverman (2007), our participants indicated moderately positive attitudes toward physical education, and no gender difference was found for attitude scores. Our findings also agreed with those showing decline in attitudes toward physical education as students progressed in grade level (Subramaniam \& Silverman, 2007; Prochaska, 2003). In our study, students in grade 9 had a lower score than those in the other two grades. Studies from Western countries indicated the decline in attitude maybe due to the repetitive nature of activities: students in upper grades may become bored when teachers use the same activities and sports every year (Carlson, 1995). The difference between grades was also attributed to the developmental differences (cognitive and social-emotional) among these groups (Subramaniam \& Silverman, 2007; Chatterjee, 2013). These two explanations may be applied to our study. However, we also need to notice the education culture difference between China and Western countries (Adams \& Sargent, 2009; Roberts \& Tuleja, 2008; Sun et al., 2012). In our participants, students in grade 9 have to face an important transitional examination to enter senior high school. The high academic burden and pressure due to high parental expectations and fierce competitions with their peers during the final year may hinder their enjoyment of physical education classes.

Several studies showed that students in urban schools had more positive attitudes toward physical education than those in rural schools (Abraham, 2013; Chatterjee, 2013). It was supposed that urban schools have more opportunity for running physical education programs properly as there is more funding, facility, and equipment (Chatterjee, 2013). On the contrary, in our study, students from the suburban district had a higher score compared to their peers in the urban district. One possible explanation is that students in urban areas experience more stress from parents to obtain good grades, peer pressure, a competitive environment in the schools, and teacher demand for good grades, which may influence their attitudes toward physical education (Taragar, 2009). Since we did not survey the environment of physical education in school and out of school and only a small number of schools participated in this study, these findings are not easy to interpret. Therefore, a recommendation for future research is that environmental factors of physical education and physical activity in and out of schools should be surveyed, and more schools from various locations (urban, suburban, and rural) need to be involved in the future.

The mixed linear model results in our study showed that the school plays a more important role in student attitudes than school location (urban, suburban). Student attitudes varied from one school to another, ranging from $70.5 \pm 14.7$ to $85.4 \pm 11.4$. Previous studies have indicated that the school environment such as status of physical education in the curriculum, curriculum content, teacher behavior, class atmosphere, and facilities, was related to students' attitudes toward physical education (Bibek, 2007; Trudeau \& Shephard, 2005). Thus, further investigation of the difference of environment for physical education between schools may be useful to help local schools properly design and implement physical education.

The findings of this study indicate that the reliability and validity of SPEA are acceptable for the assessment of attitude toward physical education in Chinese students. Attitude scores differed between grade levels, schools, and areas. Unresolved issues and challenges have been identified in the present study when attempting to ana- 
lyze students' attitudes toward physical education. To better understand students' attitudes toward physical education, further study is warranted with a view toward environment of physical education in and out of schools and more representative samples of schools from various locations.

\section{Acknowledgements}

This research was supported by grant of GCOE in Waseda University. The funders had no role in study design, data collection and analysis, decision to publish, or preparation of the manuscript. The author declares that there is no conflict of interest.

\section{References}

Abraham, B. (2013). Attitude of Urban and Rural School Students towards Physical Education. International Journal of Movement Education and Social Science, 2, 76-77.

Adams, J., \& Sargent, T. (2009). Curriculum Transformation in China: Trends in Student Perceptions of Classroom Practice and Engagement. Chicago, Illinois: Association of Asian Studies Conference.

Bibek, J. M., Goodwin, S. C., \& Orsega-Smith E. M. (2007). High School Students’ Attitudes toward Physical Education in Delaware. The Physical Education, 64, 192-203.

Biddle, S. H. J., \& Mutrie, N. (2001). Psychology of Physical Activity: Determinants, Well-Being and Interventions. New York: Routledge.

Bland, J. M., \& Altman, D. G., (1997). Cronbach’s Alpha. British Medical Journal, 314, 572. http://dx.doi.org/10.1136/bmj.314.7080.572

Browne, M. W., \& Cudeck, R. (1993). Alternative Ways of Assessing Model Fit. In K. A. Bollen, \& J. S. Long (Eds.), Testing Structural Equation Models (pp. 136-162). Newbury Park, California: Sage.

Byrne, B. M. (1989). A Primer of LISREL: Basic Applications and Programming for Confirmatory Factor Analytic Models. New York: Springer-Verlag. http://dx.doi.org/10.1007/978-1-4613-8885-2

Carlson, T. B. (1995) We Hate Gym: Student Alienation from Physical Education. Journal of Teaching Physical Education, 14, 467-477.

Chatterjee, S. (2013). Attitudes toward Physical Education of Schools Going Adolescents in West Bengal. International Journal of Engineering Science and Technology, 2, 6068-6073.

Cothran, D. J., \& Ennis, C. D. (1998). Curricula of Mutual Worth: Comparisons of Students' and Teachers’ Curricular Goals. Journal of Teaching Physical Education, 17, 307-326.

Fan, X., \& Sivo, S. A. (2007). Sensitivity of Fit Indices to Model Misspecification and Model Types. Multivariate Behavioral Research, 42, 509-529. http://dx.doi.org/10.1080/00273170701382864

Gallahue, D. L., \& Donnelly, F. C. (2003). Developmental Physical Education for All Children (4th ed.). Champaign, IL: Human Kinetics.

Hills, A. P., Andersen, L. B., \& Byrne, N. M. (2011). Physical Activity and Obesity in Children. British Journal of Sports Medicine, 71, 866-870. http://dx.doi.org/10.1136/bjsports-2011-090199

MacCallum, R. C., \& Hong, S. (1997). Power Analysis in Covariance Structure Modeling Using GFI and AGFI. Multivariate Behavioral Research, 32, 193-210. http://dx.doi.org/10.1207/s15327906mbr3202_5

Marsh, H. W., Balla, J. R., \& McDonald, R. P. (1988). Goodness-of-Fit Indexes in Confirmatory Factor Analysis: The Effect of Sample Size. Psychological Bulletin, 103, 391-410. http://dx.doi.org/10.1037/0033-2909.103.3.391

McKenzie, T. L. (2003). Health-Related Physical Education: Physical, Activity Fitness, and Wellness. In: S. Silverman, \& C. D. Ennis (Eds.), Student Learning in Physical Education: Applying Research to Enhance Instruction (2nd ed., pp. 207-226). Champaign, IL: Human Kinetics.

Pate, R. R., \& O’Neill, J. R. (2008). Summary of the American Heart Association Scientific Statement: Promoting Physical Activity in Children and Youth: A Leadership Role for Schools. Journal of Cardiovascular Nursing, 23, 44-49. http://dx.doi.org/10.1097/01.JCN.0000305056.96247.bb

Portman, P. A. (1995). Who Is Having Fun in Physical Education Classes? Experiences of Six-Grade Students in Elementary and Middle Schools. Journal of Physics Teacher Education, 14, 445-453.

Prochaska, J. J., Sallis, J. F., Slymen, D. J., \& McKenzie, T. L. (2003). A Longitudinal Study of Children’s Enjoyment of Physical Education. Pediatric Exercise Science, 15, 170-178.

Roberts, E., \& Tuleja, E. A. (2008). When West Meets East Teaching a Managerial Communication Course in Hong Kong. Journal of Business and Technical Communication, 22, 474-489. http://dx.doi.org/10.1177/1050651908320423 
Silverman, S., \& Subramaniam, P. R. (1999). Student Attitude toward Physical Education and Physical Activity: A Review of Measurement Issues and Outcomes. Journal of Physics Teacher Education, 19, 96-124.

Subramaniam, P. R., \& Silverman, S. (2000). Validation of Scores from an Instrument Assessing Student Attitude toward Physical Education. Measurement in Physical Education and Exercise Science, 4, 29-43. http://dx.doi.org/10.1207/S15327841Mpee0401_4

Subramaniam, P. R., \& Silverman, S. (2007). Middle School Students' Attitudes toward Physical Education. Teaching and Teacher Education, 23, 602-611. http://dx.doi.org/10.1016/j.tate.2007.02.003

Suhr, D. (2006). Exploratory or Confirmatory Factor Analysis? Proceedings of the 31st Annual SAS® Users Group International Conference. Cary, NC: SAS Institute Inc., Paper Number: 200-31.

Sun, J. D., Dunne, M. P., \& Hou, X. Y. (2012). Academic Stress among Adolescents in China. Australasian Epidemiologist, 19, 9-12.

Taragar, S. (2009). Stressors among the Students of High School. Master Thesis, Bangalore: University of Agricultural Sciences.

Trudeau, F., \& Shephard, R. J. (2005). Contribution of School Programmes to Physical Activity Levels and Attitudes in Children and Adults. Sports Medicine, 35, 89-105. http://dx.doi.org/10.2165/00007256-200535020-00001

Widaman, K. F., \& Thompson, J. S. (2003). On Specifying the Null Model for Incremental Fit Indices in Structural Equation Modeling. Psychological Methods, 8, 16-37. http://dx.doi.org/10.1037/1082-989X.8.1.16

Wilson, K. A., Dowling, A. J., Abdolell, M., \& Tannock, I. F. (2000). Perception of Quality of Life by Patients, Partners and Treating Physicians. Quality of Life Research, 9, 1041-1052. http://dx.doi.org/10.1023/A:1016647407161 
Scientific Research Publishing (SCIRP) is one of the largest Open Access journal publishers. It is currently publishing more than 200 open access, online, peer-reviewed journals covering a wide range of academic disciplines. SCIRP serves the worldwide academic communities and contributes to the progress and application of science with its publication.

Other selected journals from SCIRP are listed as below. Submit your manuscript to us via either submit@scirp.org or Online Submission Portal.
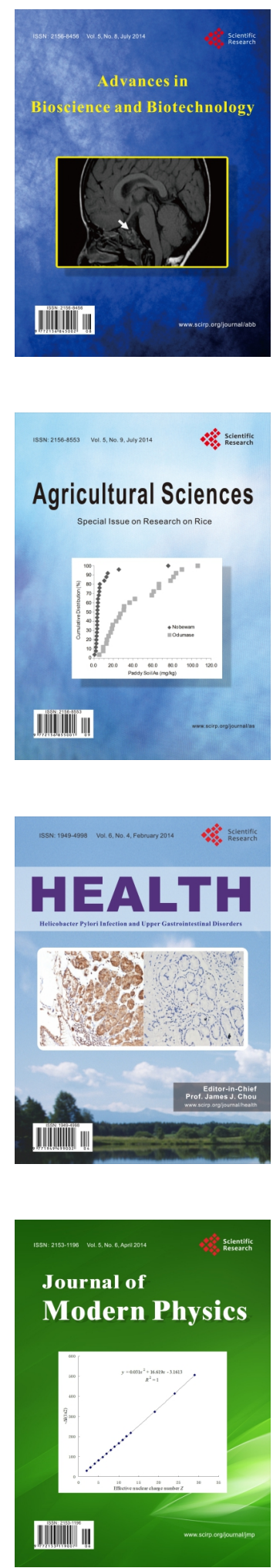
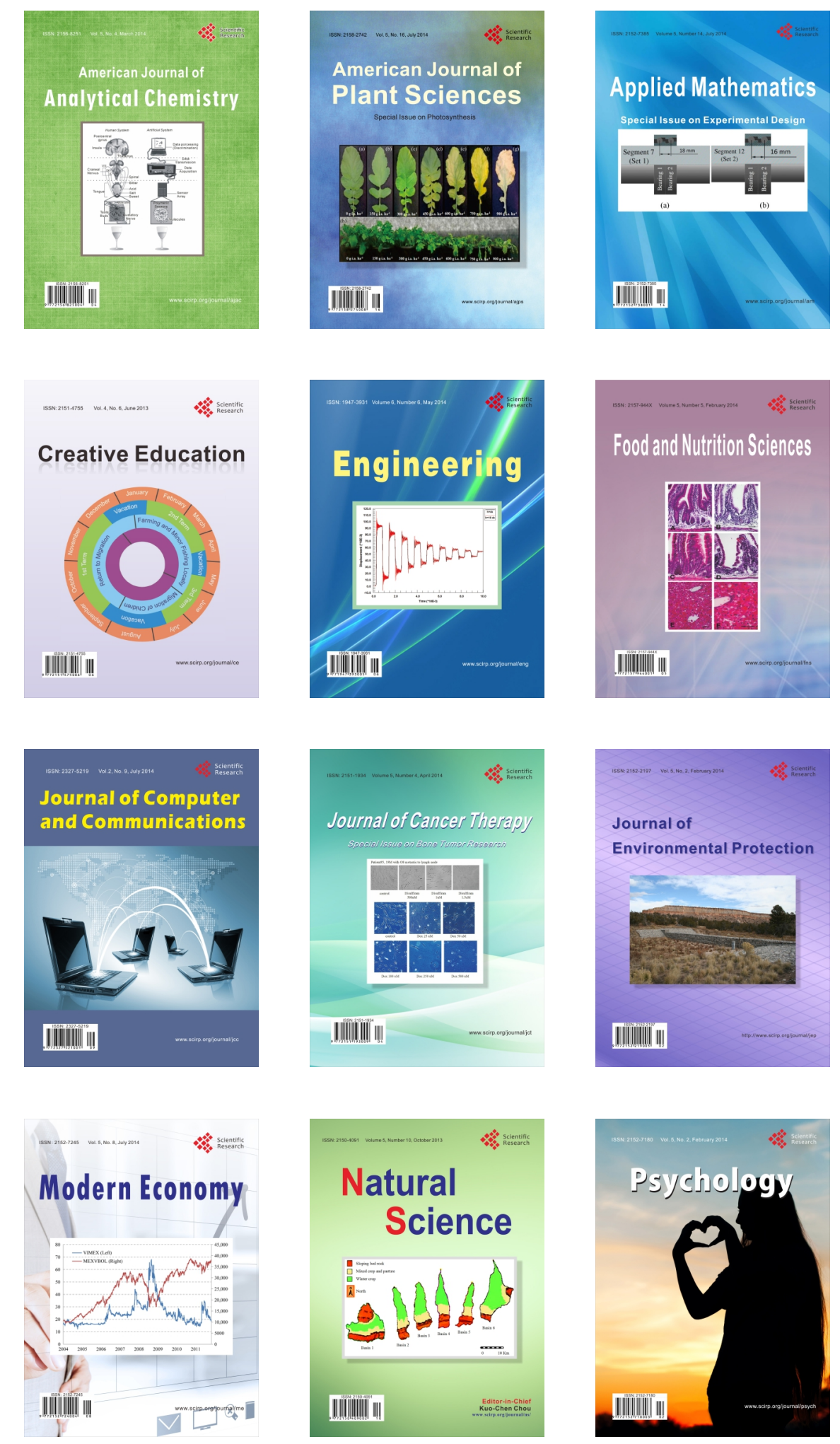